\title{
Fazer da Matemática Problema a ser Inventado Inventando Formação
}

\author{
Margareth Aparecida Sacramento Rotondo'
}

'Universidade Federal de Juiz de Fora (UFJF), Juiz de Fora/MG - Brasil

RESUMO - Fazer da Matemática Problema a ser Inventado Inventando Formação. Este artigo traz um evento que se deu em salas de aulas da formação de professores e professoras que ensinarão matemática nas séries iniciais. Na tensão de um vivido e com a atenção num vivido põe a pensar a formação de professores e professoras como inquietude e processualidade na experiência. Aproximando-se das filosofias da diferença, principalmente em Foucault e Deleuze, faz ação da teoria e ação da prática, no revezamento teoria-prática, dando a pensar a formação ao fazer da matemática problema a ser inventado. A produção matemática dá condições da invenção na formação de professores e professoras.

Palavras-chave: Formação de Professores e Professoras. Processualidade. Experiência.

\begin{abstract}
Making Mathematics a Problem to Be Invented When Inventing Education. This paper presents an event that occurred in classrooms for education of teachers who will teach mathematics in the Elementary School. In the tension of an experienced and with attention on an experience, it leads to think about the education of teachers as restlessness and processuality in the experience. Approaching the philosophies of difference, especially in Foucault and Deleuze, it makes action from the theory and action from the practice, alternating theory and practice, leading to think on education when making mathematics a problem to be invented. The mathematics production provides for the invention in the education of teachers.
\end{abstract}

Keywords: Teachers' Education. Processuality. Experience.

Educação \& Realidade, Porto Alegre, v. 39, n. 4, p. 1071-1087, out./dez. 2014. 1071 Disponível em: <http://www.ufrgs.br/edu_realidade> 
Fazer da Matemática Problema a ser Inventado Inventando Formação

[...] agora quero ver se consigo prender o que me aconteceu usando palavras.

Ao usá-las estarei destruindo um pouco o que senti-mas é fatal.

Clarice Lispector

\section{Produzindo um Cenário, Cenário em Palavras: cenário- narrativo}

Uma professora com vinte e sete anos de atuação em salas de aulas diversas. Anos finais do Fundamental, Médio, Superior. Escolas públicas, escolas particulares. Cursos superiores: Administração, Economia, Turismo, Processos Gerenciais. Percorrendo os conteúdos da matemática escolar, da estatística e do cálculo. Professou também para o Fundamental, séries iniciais: aulas particulares e filhas. Nos últimos três anos: aposentada, rede particular de ensino. Tornou-se professora em universidade pública. O novo se faz presença: formar professores e professoras que ensinarão matemática. Com esse novo, um desafio: formar professores e professoras que ensinarão matemática nas séries iniciais.

Alunos e alunas dessa professora. Muitos adolescentes, muitos. Também jovens adultos ainda sem participar do mercado de trabalho, experimentando o viver acadêmico, esperançosos por um futuro. Outros adultos, muitos, já no mercado de trabalho anos a fio, experientes da vida, da lida, desejosos por uma ascensão na vida profissional como efeito de uma entrada em um curso superior. Num curso de Pedagogia: mulheres, muitas mulheres. Em três anos, em seis turmas: quatro alunos. Alunos e alunas, alguns jovens adultos. Outros não, mais velhos. Desejos bem próximos aos que a professora já conhecia.

Uma questão se apresenta àqueles alunos e alunas do curso de Pedagogia em sua primeira aula: Como tem sido minha experiência em matemática? Questão que dispara vozes que desestabilizam uma professora-aposentada-experiente. Uma voz: quando me lembro de matemática me vêm à cabeça os bons momentos na escola - Ensino Fundamental. Tudo era bem simples e fácil, mas com o passar dos anos, vi que a matemática era bem mais complicada. Outra: nunca fui boa aluna de matemática, terminei o colegial em 1992. Lembro-me das chamadas de tabuada, que eram um verdadeiro terror, tudo era decorado e esquecido em seguida. E outra: com exceção dos conteúdos que aprendi na escola como juros, porcentagem e regra de três, não vejo como outros conteúdos me foram úteis. Contudo, é inquestionável a importância da matemática na minha vida. Em poucas vozes: sempre me dei bem em matemática, aprendia a técnica e fazia, até ajudava meus colegas nas avaliações. Em muitas outras, coro: na hora de decidir o que fazer no vestibular, queria qualquer curso que não tivesse a área de exatas, nada de matemática.

Aquela professora vinha, há muito, descontente com a relação ensino-aprendizagem. Ela, bem sucedida em matemática, deveria ter

1072 Educação \& Realidade, Porto Alegre, v. 39, n. 4, p. 1071-1087, out./dez. 2014. Disponível em: <http://www.ufrgs.br/edu_realidade> 
como resultado alunos bem sucedidos, pensava. Mas, isso não se deu. No início de sua carreira, decidiu aprender mais matemática: foi a um curso de especialização em Matemática. Mais Cálculo, mais Análise Matemática, mais Geometria, mais... Quem sabe se soubesse mais matemática, daria conta? Pensava. Mas, depois disso continuava a ensinar, ensinar e poucos aprendiam. Começou a conversar com aquilo. Incomodada, buscou por outro lugar, um curso de especialização em educação matemática. Não resolveu. Não era para resolver. Encontrou interlocutores. Pôde problematizar a produção matemática, a produção de significados em matemática, a formação. E, a partir daí, começou a problematizar: a produção de subjetividades, a produção de subjetividades ao se produzir matemática, a cognição, as políticas cognitivas. Professava pesquisando. Pesquisava professando. Foi por aí que encontrou com aquelas narrativas daqueles e daquelas que optaram por estar ali no curso de Pedagogia. Ainda assim, o novo, sempre o novo. Como abalar as concepções de matemática encarnadas nestes corpos? Como estremecer o lugar de fracassado em matemática já estabelecido? Como inquietar o lugar do bem sucedido em matemática que apenas repete técnicas? Como problematizar a ligação matemática-aprendizagem-utilidade? Como desestabilizar uma visão matemática platônica ou pitagórica? Como guerrear com uma concepção preexistente da matemática? Como?

Um plano se pôs em ação durante duas disciplinas²: fazer da matemática problema a ser inventado. Pôr a problematizar desde as concepções que se tem de matemática, partindo de questões do tipo: como tem sido a minha experiência em matemática? e como seria um mundo

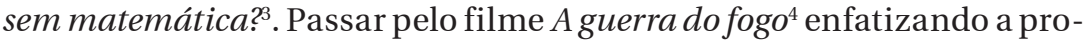
dução humana apresentada na película ao produzir o fogo e problematizando a produção humana que se dá no viver ao produzir matemática. E, ao longo dos dois semestres nas disciplinas, trazer os conteúdos das séries iniciais através do que foi chamado de atividade. Nas atividades, abordagens didático-metodológicas. Quase todas inquietantes, moviam o pensar. Algumas, não vingavam, pensava a professora. E para um próximo semestre ou eram descartadas ou rasuradas. Sempre, após as atividades, textos de educadores matemáticos, bem próximos ao vivido, sussurrando com a experiência; alguns dizendo das abordagens metodológicas, outros daquela experiência vivida, então, por outros.

Por agora, cenário apresentado. Traremos uma das atividades, no movente deste cenário: atividade de medidas não padronizadas. Atuando: professora, alunos e alunas em formação num curso de Pedagogia, um professor-substituto ${ }^{5}$ e uma aluna-monitora ${ }^{6}$ das disciplinas.

Acoplada à professora, para o cenário, vai também a pesquisadora: uma e muitas dela. Na inquietude da professora junto ao seu fazer nas salas de aula que frequenta, vai a pesquisadora. Sala aula: campo de pesquisa. A pesquisadora leva consigo uma de muitas de suas questões.

Educação \& Realidade, Porto Alegre, v. 39, n. 4, p. 1071-1087, out./dez. 2014.1073 Disponível em: <http://www.ufrgs.br/edu_realidade> 
Fazer da Matemática Problema a ser Inventado Inventando Formação

Questão que se faz junto à formação concebida em sua processualidade: como, ao produzir matemática, produzimos outro de nós mesmos e também outros do mundo? Como método de pesquisa, a pesquisadora atenta que não há caminhos antecipados. O que há por fazer é a travessia. O método se faz no fazer do vivido: na tensão e com atenção, sempre com rigor junto à experiência ${ }^{7}$. Como recursos, ela carrega: escritos, falas, fotos e áudios ${ }^{8}$.

\section{Atividade com Medidas não Padronizadas}

Salas de aulas distintas, tempos distintos. Já que nunca somos os mesmos, movimento com isso. Que venha um cenário e seu movimento.

Uma proposta de trabalho é aberta: Atividade com medidas não padronizadas. O nome dado à atividade não é apresentado aos alunos e às alunas. Nada de dizer de não padrão, nem do padrão. Alunos e alunas se organizam em pequenos grupos. Cada grupo recebe: uma região retangular em papel; um pedaço de barbante ${ }^{9}$, chamado de unidade de medida de comprimento; um quadrado, chamado de unidade de medida de área. A região retangular a ser medida é a mesma para todos os grupos. Quatro unidades de medidas de comprimento diferentes estão distribuídas pela sala de aula. E, também, quatro unidades de medidas de área diferentes (Foto 1). Há, em sala de aula, grupos com a mesma unidade de medida de comprimento e a mesma unidade de medida de área.

Proposta feita: mensurar o perímetro e a área daquela região retangular comum a todos os grupos.

Foto 1

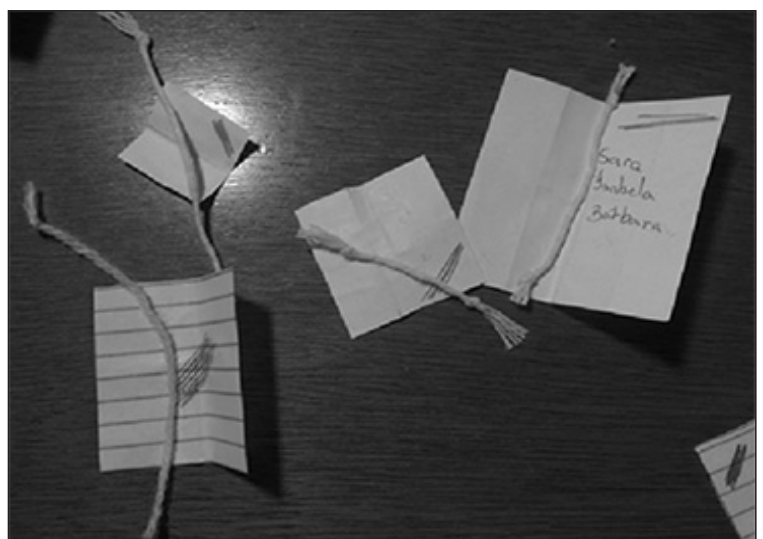

Fonte: pesquisa do autor - salas de aulas do Curso de Pedagogia - UFJF.

A tarefa começa a ser realizada. Barulho. Mede primeiro com o barbante. Um, dois, três, quatro,... Mas, e quando virar, quando mudar 
de lado, continua contando? Primeira questão. Monitora em ação: o que vocês acham? E seguem medindo. Ah, continua. Barulho. Não, olha só! Mede esses dois lados e depois dobra. Esse lado é igual a esse. E esse igual ao da frente. Ah, é! Hum, mas e agora? Faltou um pedacinho desse lado para medir! Ih, professora, como faz, não cabe medida inteira? Professora em ação: o que vocês podem fazer? Ah, não sei... Essa é a unidade de comprimento que vocês têm! Pode ir dobrando? Monitora em ação: o que acham? E começam a dobrar barbante. Ah, então é parte, é fração. E anotam. E contam. E medem. E dobram. E medem. E anotam... E aparecem quantidades inteiras da unidade. E aparecem pedaços da unidade. Partes do barbante, frações da unidade de comprimento. E somam inteiros. E somam frações. E transformam fração em número decimal. E somam inteiros. E somam frações. E transformam fração em número decimal. E somam inteiros com fração. E somam inteiros com decimal. Medidas, contagens, dobras, anotações, cálculos. Questões distintas, medições distintas, tempos distintos: grupos distintos. Corpo-monitora e corpo-professora: atentos. Professam, sem postar verdades. Levantam inquietações. Produção matemática em invenção. Alunos e alunas em invenção.

Tomam os quadrados. Seguem na proposta. Agora mensurar área da região retangular usando o quadrado, usando a unidade de área (Foto 2). Como fazer isto? Pode riscar a região? Monitora em ação: pode sim. Já tinha riscado. Ah, não, não quero riscar, vou só marcando.

\section{Foto 2}

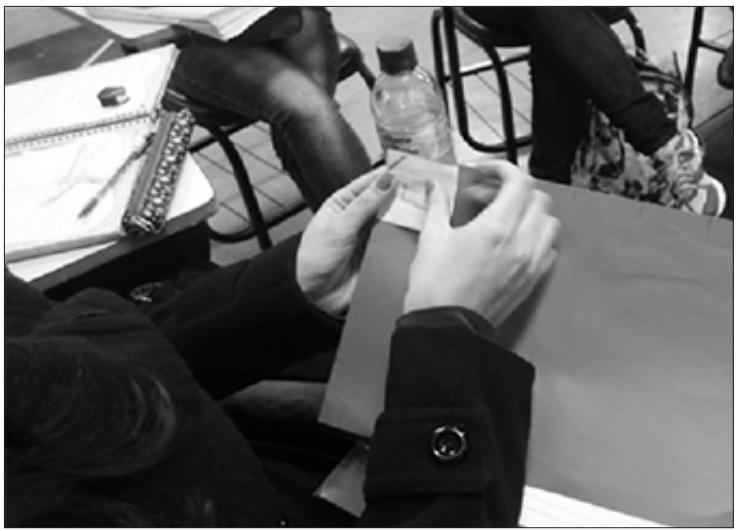

Fonte: pesquisa do autor - salas de aulas do Curso de Pedagogia - UFJF.

E sobrepõe quadrado na região. Desenha quadradinho. E risca. E risca. E apaga. Não está dando certo. E só marca. E perde a contagem. E perde a marca. E vem o incômodo. Ih, não cabe? Não? E professora em ação: como vocês vão fazer? Como assim, professora? Não sei. Ah, já sei, não dobrou barbante? É. Vamos dobrar! Pode, professora? E professora em ação: silêncio, olhares. E dobram quadradinho. E somam pedaço daqui

Educação \& Realidade, Porto Alegre, v. 39, n. 4, p. 1071-1087, out./dez. 2014.1075 Disponível em: <http://www.ufrgs.br/edu_realidade> 
Fazer da Matemática Problema a ser Inventado Inventando Formação

com pedaço dali. E surge quadrado inteiro. E ficam sobrando pedaços na região retangular a ser mensurada. Mas, não dão quadrados inteiros! E agora? Hum, põe o pedaço que deu? E pode? E monitora em ação: o que você acha? Ah, é fração. E monitora em ação: silêncio. É, é fração. Por que não? Vamos lá, quantidade inteira mais esta parte. E anotam. E contam. E medem. E dobram. E medem. E anotam... E aparecem quantidades inteiras da unidade. E aprecem pedaços da unidade. Partes do quadrado, frações da unidade de área. E somam inteiros. E somam frações. E transformam fração em número decimal. E somam inteiros com fração. E somam inteiros com decimal. Medidas, contagens, dobras, anotações, cálculos. Questões distintas, medições distintas, tempos distintos: grupos distintos.

Foto 3

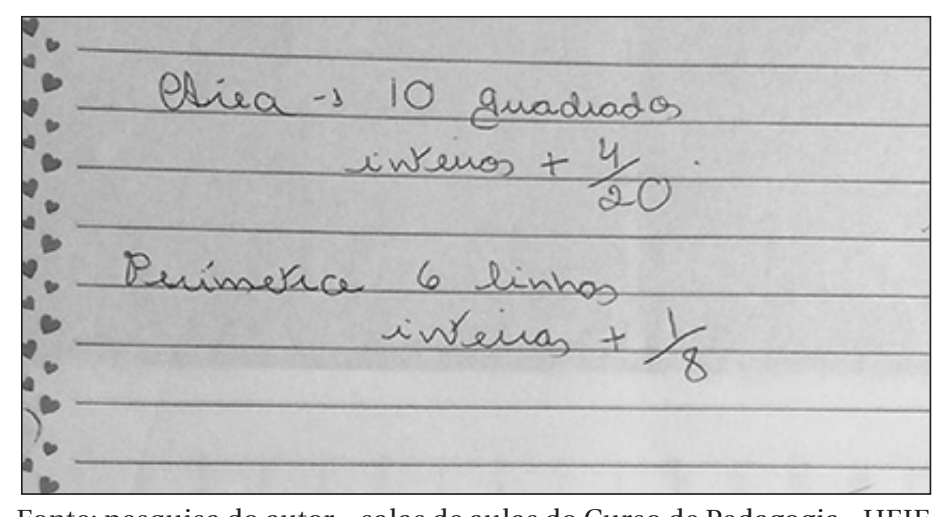

Fonte: pesquisa do autor - salas de aulas do Curso de Pedagogia - UFJF.

Corpo-monitora e corpo-professora: atentos. Professam abalando a profecia de que tudo sabem. Inquietam pensares que não têm segurança do caminho, dos passos. Um guia num agogós do grego, numa condução. São corpos que se produzem com novos e outros corpos, que fazem com que a criança, o paidós, seja inventada em cada um daqueles alunos e daquelas alunas em sua produção matemática, ao fazerem da matemática problema também a ser inventado. Sem posse do caminho, as crianças inventadas em alunos e alunas, inventam uns professores e professoras em formação. Caminhos, trilhas, escapes, becos, fugas. Produção matemática em invenção ao fazer da matemática problema numa formação de professores e professoras.

Findam-se as mensurações. De novo ao grupo maior. Para o quadro vão as anotações de perímetros e áreas ${ }^{10}$.

1076 Educação \& Realidade, Porto Alegre, v. 39, n. 4, p. 1071-1087, out./dez. 2014 Disponível em: <http://www.ufrgs.br/edu_realidade> 
Foto 4

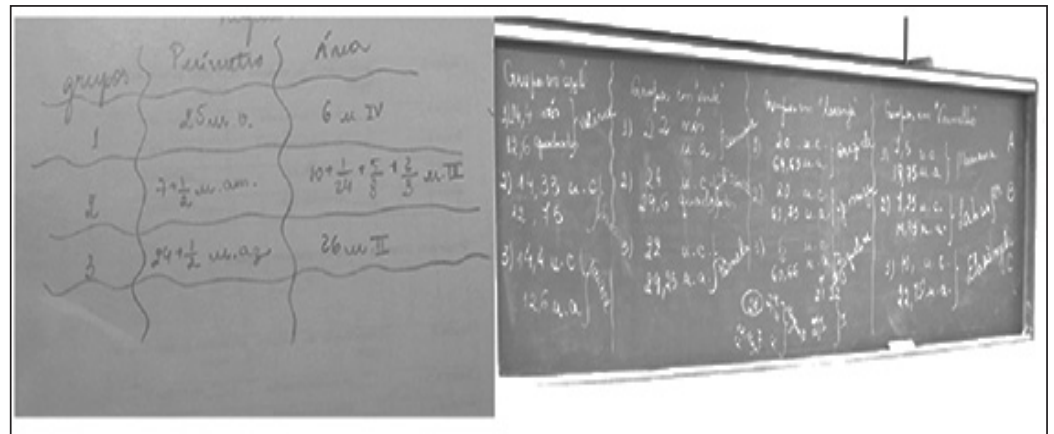

Fonte: pesquisa do autor - salas de aulas do Curso de Pedagogia - UFJF.

Grupos com mesma medida de unidades comparam seus resultados. Alguns próximos, outros não. Ah, pouco diferença, foi no jeito de dobrar o barbante. Foi no jeito de dobrar o papel do quadradinho. Hum, muita diferença. Ih, o que houve? Se a região a ser medida é a mesma, a unidade é a mesma, tinha que dar próximo, né? Conferem medidas das unidades. Barbante com barbante. Quadrado com quadrado. Conferem os perímetros e as áreas. Ah, foi aqui, não é esse valor, o meu é que está mais próximo. Ih, não é essa fração. Hum, errei nesta conta. E vão se aproximando.

Um novo problema vai sendo produzido. Há também quatro unidades de comprimentos distintos pela sala, perímetros com resultados distintos. E também quatro unidades de área distintas em sala de aula, áreas com resultados distintos. Como, se a região retangular entregue aos grupos era idêntica? Problema: como falar a respeito das mensurações da área e do perímetro daquela região retangular de um modo comum entre eles?

Uma próxima etapa. Grupos maiores compostos por quatro grupos distintos trazendo, cada um deles suas unidades de comprimento e unidades de área, distintas entre si. Cada um dos grupos menores foi chamado de comunidade. Um grupo maior tinha agora quatro unidades de comprimento distintas e quatro unidades de área distintas, trazidas das quatro comunidades.

Uma nova proposta se apresenta em questões aos grupos maiores: como falar do perímetro e da área de um mesmo objeto utilizando mensurações distintas? Como vocês resolveriam esse problema? Há também a solicitação de que relatem a reunião preparando um texto.

Vozes surgem. Algumas vozes. Uma comunidade deu a ideia de comparar as cordas de barbante. Ver qual era a maior e adotá-la como modelo. Outra sugeriu que comparássemos os barbantes, tipo assim: a medida do barbante 1 é o dobro do 2, e assim por diante. Mas, isso acabou não dando certo, nem sempre uma cordinha era quantidade inteira de outra. Então, surgiu a ideia de escolher uma corda padrão sem relacioná-

Educação \& Realidade, Porto Alegre, v. 39, n. 4, p. 1071-1087, out./dez. 2014.1077 Disponível em: <http://www.ufrgs.br/edu_realidade> 
Fazer da Matemática Problema a ser Inventado Inventando Formação

-los. Perguntamos ao professor substituto, nossa professora estava em um seminário, se poderíamos criar uma unidade nova. Ele disse para nós decidirmos. Essa ideia de impor uma medida desagradou a alguns. Não era democrático, diziam. E também, que criando uma medida nova, as que já existiam iam ser desconsideradas. Isso parecia desagradar a muitos. Perder o que já tinham feito até então. De repente, um componente de uma comunidade cortou uma corda e disse que aquela seria a nova unidade. Mas, outro componente, de outra comunidade, não aceitou. Como a coisa parecia estar difícil de entrar em consenso surgiu à ideia de unir todos os barbantes. Os barbantes foram unidos. Mas, mesmo assim uma componente de uma comunidade não concordou. Parecia não ter sido ouvida. Continuaram com a coisa. Já queriam até dar nome à nova unidade de comprimento! Como o fio que estávamos usando era da cor amarela, veio o nome: Amarelo. Ainda não estava bom para alguns. Havia um desconforto. Veio de um, a solução: pegar aquele fio amarelo e repartir em quatro partes iguais, já que eram quatro grupos. Feito. Cada grupo ficou com um pedaço do fio amarelo. Então, essa era a nova medida de unidade de comprimento. E recebeu o nome de Amarelo mesmo. Comparamos nossas antigas medidas de comprimento com o Amarelo e ficou assim (Foto 5):

Foto 5

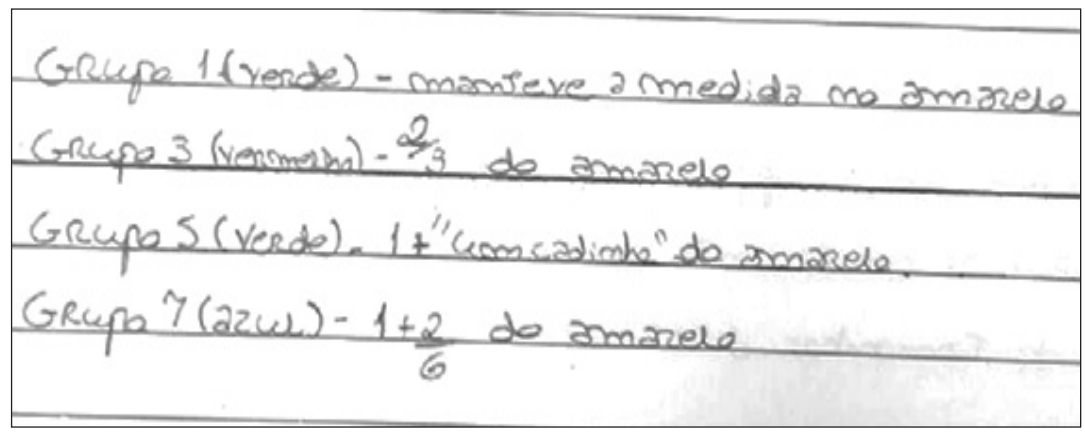

Fonte: pesquisa do autor - salas de aulas do Curso de Pedagogia - UFJF.

Outras vozes. Primeiro pensamos na redução de um quadradinho para outro. O problema é que temos um objeto comum e medidas discrepantes. O conflito surge quando a Elzi acredita que medir a área e o perímetro com o quadradinho, é melhor. Pois, depois a gente soma a quantidade de vezes que o quadradinho pequeno cabe nos outros três maiores. Já a Lina acredita que é mais fácil fazer o contrário, medindo o padrão da área e do perímetro com o quadrado maior. Por votação, decidimos que é mais fácil utilizar o quadrado maior para medir. Estipulamos que cada lado do quadrado maior é igual a 1 . O quadrado maior tem a área $1 \times 1$. Quando utilizamos um quadrado que possui um quarto da área total, ele terá a medida meio $x$ meio.

E outras vozes vieram... As folhas que cada grupo recebeu para medir perímetro e área eram iguais, mas os instrumentos eram diferentes. Por

1078 Educação \& Realidade, Porto Alegre, v. 39, n. 4, p. 1071-1087, out./dez. 2014. Disponível em: <http://www.ufrgs.br/edu_realidade> 
isto tínhamos resultados diferentes. Então, o que fazer para todos terem o mesmo perímetro e área? Seria necessário padronizar as unidades de comprimento e de área utilizados. Dessa forma, decidimos unir todos os barbantes para que, a partir de um só, o padrão, fosse possível encontrar um só resultado para o perímetro. Já para medir a área, a estratégia inicial foi a de formar um quadrado único com a união dos quadrados. Mas, não deu certo, já que não formamos um novo quadrado (Foto 6). Então, utilizamos outra estratégia: formar com o barbante padrão um quadrado, a nossa unidade de medida de comprimento padrão seria o perímetro de um quadrado. Com o barbante padrão montamos um quadrado que possibilitasse medir a área daquela região que todos tinham.

Foto 6

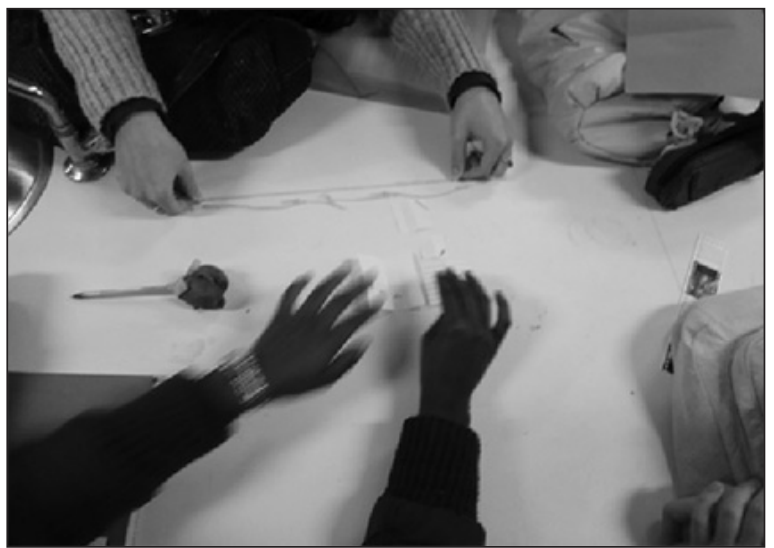

Fonte: pesquisa do autor - salas de aulas do Curso de Pedagogia - UFJF.

Outro lugar se produz em invenção numa conversa ${ }^{11}$. Fazer da matemática problema inventava outros do professor-substituto, da monitora e da professora.

Uma conversa a três e outros muitos. Um professor-substituto chama à conversa. Olha só, cheguei em casa com a aula da Pedagogia em mente. Melhor, no corpo. Surgiram as seguintes coisas, que eu tinha que compartilhar. Bom, ficamos discutindo a questão dos papéis da História da Matemática (HM) na sala de aula e acabei pensando o seguinte: se essa atividade que foi proposta, escapa da questão de pensar a HM enquanto uma ilustração do desenvolvimento do conteúdo matemático ao longo da história, acho que ela também acaba escapando a uma noção de história teleológica, de uma história de caminho necessário na produção das medidas, no nosso caso... Dessa maneira, não passamos resumidamente pelas etapas de desenvolvimento das medidas de modo, digamos, construído, mas constituímos outra coisa... A meu ver, a história acabou servindo como o disparador de processos de invenção que acabou nos surpreendendo exatamente pela imprevisibilidade dos resultados a que aqueles alunos e alunas chegaram. E um dizer vai sendo invadido por uma professo-

Educação \& Realidade, Porto Alegre, v. 39, n. 4, p. 1071-1087, out./dez. 2014.1079 Disponível em: <http://www.ufrgs.br/edu_realidade> 
Fazer da Matemática Problema a ser Inventado Inventando Formação

ra. Não há repetição histórica, já que as necessidades são outras. Mesmo próximas, não há, ali, a questão da sobrevivência, por exemplo. Constituímos, sim, outra coisa. Não estávamos passando por uma linha histórica já vivida. Construía-se, ali, uma história naquele grupo. Outra voz invade a conversa, uma professora em formação-monitora. A história da matemática pode servir efetivamente como recurso ao ensino quando não se restringe aos dados biográficos de certo matemático ou de certo povo, e sim quando a construção histórica é experienciada. No entanto, a remontagem desse ambiente seria inevitavelmente inadequada, uma vez que, por mais que procuremos nos aproximar de um contexto histórico, somos indivíduos que vivem e interagem com as tecnologias do século XXI. Assim, chego à conclusão, a partir da aula desta semana, que o auxílio mais provável, digamos assim, é que a história nos oferece as condições de reinventar as construções dos objetos e conceitos matemáticos que utilizamos, no sentido de construí-los a partir de uma investigação onde surgirão coisas que não podemos prever. E volta a voz do professor-substituto também em formação. Ao estranhar um ente cultural tão comum como a medida, as alunas e os alunos acabaram por conseguir problematizar esta noção e, ainda que operando dentro desse conteúdo, inventar problemas extremamente intrincados e complexos que, talvez, não fossem possíveis numa abordagem metodológica, digamos, tradicional do conteúdo medida. Professora, em sua processualidade, volta. Isso mesmo!!! Interessante pensar que um ente cultural já naturalizado, utilizado e posto pronto em seus sentidos teve que ser esfacelado para outra, ou quem sabe, outras produções de significados. Voz monitora dispara em produção. Eaté porque esse ente pode, até naquele momento, ainda não ter sido pensado. Professor-substituto desfazendo-se em processualidade e fazendo-se outro. $A$ HM como disparador de um processo inventivo... é aí que estou... Monitora embriaga-se. Com licença, posso entrar nesse território também?! Professora, numa processualidade. Que tal a história da matemática sendo inventada, criada, produzida?

E uma unidade padrão de comprimento foi sendo produzida por aqueles alunos e alunas. E uma unidade padrão de área foi sendo produzida por aqueles alunos e alunas. E uns alunos, umas alunas, uns educadores matemáticos, umas educadoras matemáticas foram sendo produzidos com aquilo que inventavam no viver daquelas salas de aula.

Para fechar a atividade, não findando com a processualidade da mesma, foram sugeridos alguns textos para as alunas e os alunos. Numa outra aula, com uma leitura prévia, um corpo-grupo se põe em produção. Vozes. Uma primeira. O interessante nessas atividades é, que antes mesmo de ler um texto, você pega para fazer. Você sentir dificuldade para fazer aquilo sem ter embasamento nenhum. A gente já está tão acostumado a fazer aquilo, já tem tanto tempo que está estabelecido, peso e medida, que a gente não para pra pensar como isso era feito. Por que isto já é tão automático na gente - o centímetro, o metro - que a gente não para, para imaginar como era feito isso aqui, como era feito antes, ter essa

1080 Educação \& Realidade, Porto Alegre, v. 39, n. 4, p. 1071-1087, out./dez. 2014 Disponível em: <http://www.ufrgs.br/edu_realidade> 
história. E aí quando você tem que fazer, você diz: Poxa, é isso mesmo! Você consegue ter uma visão depois quando você começa a ler o texto, das dificuldades que eram, porque você passou a ter aquela dificuldade para fazer aquela medida. Coisa que você lida aqui, não ia visualizar isto. A gente que acabou visualizando. E outra voz. Acho que tem a ver com olhar a matemática como historicamente construída, como um elemento que não é dado. E daí quando você nasce num mundo que já é metrificado e, às vezes, acaba não percebendo que isto é uma coisa feita pelos homens. $\mathrm{E}$ uma voz perturba. Isso é acreditar na racionalidade do homem, numa só racionalidade. O pior é pensar apenas em uma racionalidade, num lugar que só existe a verdade posta. E outras experiências vêm de outros vividos em vozes. Pois é, na escola que faço estágio as crianças começaram a medir com os palmos, para depois irem medir com centímetros. E outra... E meu pai, meu pai nunca teve estudo. É muito interessante, ele não experimenta uma calça numa loja. Ele mede no antebraço dele e dobra. Aquela medida é que tem que ser a metade da cintura. Não sei se isso vai parar de dar certo, agora ele está ficando mais barrigudinho. E vem outra, também da vida. Pois é, em uma escola da zona rural, um dia, conversando com umas crianças perguntei para elas qual era a distância da casa delas, que é um sítio, até a escola. E elas responderam que a pé dava umas duas horas. Muito legal, eu esperava tantos quilômetros e elas me responderam em tempo. Distância era mensurada em horas. Retornam à atividade realizada e ela reverbera, em vozes. É, foi uma produção coletiva, mas tinha uma relação de poder. É essa coisa de vou atender a todos os grupos é também uma questão política, né? Aquilo de ter que satisfazer a todos. É, existe uma coisa do grupo, do coletivo. E teve também quem se impôs como o Vitor, que falou a medida da unidade de comprimento vai ser a minha, a do meu grupo, tá? Vem uma voz mais professoral. O que me parece que vocês fizeram uma constituição histórica de uma medida padrão. Uma voz aluna inquieta. Pois é, a gente acaba pensando que a matemática não tem história, né? Volta a voz professoral. Poderíamos dizer assim isto é resolução de problema. Quer dizer: vocês estavam resolvendo um problema, um problema que era do coletivo. E eu posso olhar para o viés histórico da constituição de uma unidade de medida padrão em vez de dizer que existe uma. Significa que eu não vou dizer que existe uma? Não. Mas, esse um enquanto se estabelece ele tem uma constituição histórica, assim como aquilo que foi produzido em sala de aula. Que não é inferior a esse um. Só que outro está atendendo a um maior, tem uma língua maior, já oficial. Mas, eu posso ter algo atendendo a um menor. Mas, não um menor em qualidade, só no sentido de não ser o oficial e que vale para este coletivo. E vem, novamente, uma voz aluna inquieta. Neste texto que tem a história da matemática, o que eu acho bacana, é que ao trabalhar com a história da matemática você rompe com a ideia da matemática que preexiste, tal como ela é e com a ideia ocidental também. Rompe com a ideia de que a matemática ela foi uma construção só daqui, do ocidente, entendeu? Eu acho que a defesa do texto é interessante por conta disso: de mostrar para

Educação \& Realidade, Porto Alegre, v. 39, n. 4, p. 1071-1087, out./dez. 2014.1081 Disponível em: <http://www.ufrgs.br/edu_realidade> 
Fazer da Matemática Problema a ser Inventado Inventando Formação

esta criança que esta matemática é uma construção humana e que ela veio a servir às demandas de cada sociedade. Apesar de ser um instrumento de poder, assim como na época do feudalismo, que cada senhor feudal tinha a sua medida como instrumento de poder. Mas, para aquele grupo, atendia às demandas daquele grupo. O que não atendia para o outro, então não havia esse consenso. É legal ver que a matemática, nesse sentido, ela pode atender às necessidades de um grupo. Como foi o trabalho que a gente fez, só que... No nosso grupo agora, você falando sobre a questão de atender ao coletivo, à medida de cada um, utilizando uma só. O nosso, apesar da gente ter feito uma votação, que é democrática, né? A gente não foi nada democrático. A gente pegou o grandão e falou assim: esse é o melhor, então vamos fazer tudo com base nele. Desconsiderou todo o resto. A gente fez igual ao Vitor fez. Esse aqui é o mais fácil, a gente pegou a medida dele. Recortou em monte pedaços e constituiu com aquilo. Então, a gente não foi democrático como a gente achou que estava sendo: pela votação. Eu me senti o senhor feudal agora. A Lina estava com a medida grande e a Elzi com a pequenininha. A Elzi matutando que queria a pequena e a Lina, a grande. As duas disputando qual seria. E a gente definiu: É a da Lina que está certa. A gente votou na Lina e esqueceu a Elzi. Ela ficou só com o voto dela mesma. Não foi nada democrático o que a gente fez. A voz professoral implica-se. É, alguns discursos, discursos de poder, ficam no silencioso, no não dito. Então, fica para nós, um problema em questão: como, essa racionalidade imposta e suas verdades, têm nos constituído nesse lugar chamado escola?

Corpos implicados, corpos em formação.

\section{Reverberando}

Um vivido virou texto, tomou língua, já nem era ele mais. Isto é fatal. Já se torna, aqui, uma das possibilidades em escrita dos efeitos produzidos na formação e com a formação de uma professora-pesquisadora autora deste artigo junto à processualidade da formação de professores e professoras que ensinarão matemática nas séries iniciais e também aos seus efeitos. Traz uma possibilidade: fazer da teoria e da prática, ação. Nada de teoria iluminando a prática, viés idealista. Nada de prática alimentando a teoria, viés materialista. Nada de teoria e prática em interação, numa perspectiva dialética ${ }^{12}$. Teoria enquanto caixa de ferramentas. Diz Gilles Deleuze: "Uma teoria é exatamente como uma caixa de ferramentas. Nada tem que ver com o significante... É preciso que sirva, é preciso que funcione. E não para si mesmo" (apud Foucault, 2003, p. 39). Sim, uma teoria que sirva.

Sirvo-me, neste artigo, dos pensamentos de Deleuze e de Foucault, principalmente no que deram a pensar os modos de subjetivação. Não há como colar a teoria à prática, neste lugar. Nem o inverso. É preciso que sirva. Anda servindo ao pensamento no que tem dado a pensar a formação de professores e professoras que ensinarão matemática. Uma

1082 Educação \& Realidade, Porto Alegre, v. 39, n. 4, p. 1071-1087, out./dez. 2014 Disponível em: <http://www.ufrgs.br/edu_realidade> 
pesquisadora que não descola da professora. Professora em processo de formação, pesquisando. Uma professora que não descola da pesquisadora. Pesquisadora em processo de formação, professando. "Ação de teoria, ação de prática em relações de revezamento ou em rede" (Deleuze, 2006, p. 266). Com isto uma pesquisa se dá na processualidade da formação num campo invadido e composto pelo vivido em algumas salas de aulas. Com uma produção de dados junto ao fazer de uma professora, de alunos, de alunas, de uma monitora e de um professor-substituto.

E é no meio, no entre do processo de formação, que a tensão se dá. No encontro com o curso de Pedagogia para uma professora-pesquisadora colocam-se em suspensão muitos comos: como abalar as concepções de matemática encarnadas nestes corpos? Como estremecer o lugar de fracassado em matemática já estabelecido? Como inquietar o lugar do bem sucedido em matemática que apenas repete técnicas? Como problematizar a ligação matemática-aprendizagem-utilidade? Como desestabilizar uma visão matemática platônica ou pitagórica? Como guerrear com uma concepção preexistente da matemática? Como? Questões modais implicam-se com um viver. Tensionar o viver se faz necessidade. Um corpo-professora no fluxo e com o fluxo se põe em risco, inquieta-se com a formação. Uma opção se faz: fazer da matemática problema a ser inventado.

Uma pesquisadora-professora também faz uma opção: atentar-se aos fios de vida que ali se apresentam e que possibilitam o tornar-se daqueles que estão na processualidade da formação. Ela e sua questão: como, ao produzir matemática, produz-se outro de si e outros do mundo?

Neste artigo, uma opção também se faz: falar com um produzido junto ao professar-pesquisar. Um produzido no viver da processualidade na formação de professores e professoras que ensinarão matemática nas séries iniciais.

Que formação? Formação entendida enquanto processo rente ao vivido no e com o mundo. Formação na qual não há um sujeito a ser lapidado para ser professor. Formação na qual não há um sujeito a alcançar uma forma. O sujeito se faz com e no processo da formação. Faz-se, no sentido de se produzir. Não antecipado ao processo, um sujeito descontínuo, num fluxo. Então, que é isto que se faz? Na relação, com e no mundo, um si, um não eu, vai se produzindo e produzindo seu mundo. Como? Inquietando-se com o viver. Cuidando-se com o viver, num cuidado de si. "O cuidado de si é uma espécie de aguilhão que deve ser implantado na carne dos homens, cravado na sua existência, e constitui um princípio de agitação, um princípio de movimento, um princípio de permanente inquietude no curso da existência” (Foucault, 2006, p. 11). Implantar um aguilhão à carne e insistir na agitação, na inquietude, na processualidade da formação. Nada de partir do que já está posto e definido, ziguezaguear e gaguejar com a vida, permanecer na inquietude.

Educação \& Realidade, Porto Alegre, v. 39, n. 4, p. 1071-1087, out./dez. 2014.1083 Disponível em: <http://www.ufrgs.br/edu_realidade> 
Fazer da Matemática Problema a ser Inventado Inventando Formação

Pensar a formação enquanto inquietude e processualidade exige um desapego aos projetos, às metas, aos trajetos antecipados, ao conhecido e ao possível reconhecimento. Não há início nem fim. Há uma tensão no entre que se faz nas implicações com um vivido. Implicações enquanto experiências. Há uma tensão nas e uma atenção nas relações, sempre no com. No com de conviver. Há que se equipar para a produção de um si, para a produção de um professor e uma professora em formação. Tornar-se forte com e nas relações. Um si que se cuida para se empoderar num vivido e se apoderar de um modo de existir outro. A formação assim pensada exige do corpo um fluxo com e no vivido, com um si e com o outro, na experiência. Experiência pensada por Foucault não como aquela que funda o sujeito, e sim aquela que arranca o sujeito de si mesmo, num empreendimento de dessubjetivação (Castro, 2009).

Não há, na formação enquanto inquietude e processualidade na experiência, o modo para se tornar o professor e a professora. Na processualidade uns modos vão se constituindo enquanto opções na avaliação de valores e produção de outros que potencializem a vida a se produzir. Opção por modos, sempre uma política ligada a uma ética, com uma avaliação, uma produção e uma invenção de valores outros. Com isto, uma estética enquanto a possibilidade de se produzir de outras formas, uma identidade que faz valer um instante à eternidade (Foucault, 2006). Um sujeito descontínuo, impregnado ao fluxo da vida. A formação enquanto inquietude e processualidade na experiência se apresenta sempre nas relações com e no mundo. Um professor ou uma professora que não gruda ao esperado, uma formação que não tem forma nem fôrma.

Neste artigo, uma de muitas atividades que foram se compondo junto à processualidade da formação de professores e professoras que ensinarão matemática nas séries iniciais do Ensino Fundamental. Uma opção pela processualidade, então uma decisão política. Uma decisão compreendendo que o aprender a ser professor ou professora não se desloca ou se descola do que se vive na e com a educação, neste caso a educação escolar, mas não só ela. A aprendizagem e a produção de conhecimento junto à produção de modos de existir. Ação de prática, ação de teoria.

Aprendizagem e produção de conhecimento estão numa ligação direta a uma política de cognição que alimenta o viver. Uma política de cognição inventiva (Kastrup, 1999). Uma política que compreende a cognição enquanto invento e inventor. A cognição enquanto aquela que se inventa criando formas novas de operar que escapem ao universal e ao invariante, então cognição inventada. A cognição enquanto aquela que dá condições à processualidade, à criação e à transformação, então cognição inventiva. Uma política que compreende a cognição assim escapa às totalizações e às representações. Nesta política a vida e a existência são também invenções. Ao produzir conhecimento, ao produzir matemática, ao negar a recognição, possibilidades de existir de outros

1084 Educação \& Realidade, Porto Alegre, v. 39, n. 4, p. 1071-1087, out./dez. 2014. Disponível em: <http://www.ufrgs.br/edu_realidade> 
modos se produzem, outros mundos se produzem. O sujeito descontínuo, aquele do fluxo, que se põe a produzir matemática junto a uma política de cognição inventiva não se põe a reconhecer. Ele inventa e se inventa. Empodera-se ao produzir matemática, não inibe o corpo e a vida apenas no reconhecimento do já produzido. Apodera-se de uma matemática, a dele. Inventa-se um si, cuida-se de um si, empodera-se um si. Produção de conhecimento matemático levando à produção de subjetividades outras numa formação de professores e professoras, numa formação enquanto inquietude e processualidade na experiência. Ação de prática. Ação de teoria.

Tomar certo item do conteúdo das séries iniciais simples e trivial para todas e todos. Fazer com ele um movimento de investigação, um problema coletivo. Manter a tensão e a atenção na produção, no entre. Nem início nem fim, na tensão e em atenção. Dar pistas, incitar, manter o aguilhão fincado à carne: ações da professora, ações do professor-substituto e ações da monitora. Professora, professor-substituto e monitora, todos, também implicados à processualidade, em experiência, em formação. Um emaranhado: aquele que forma professores e professoras também está em formação.

Uma resolução de problemas que solicita um coletivo a estar junto, que faz com que inventem modos de operar matematicamente, a cognição inventada. Explorar e visitar outros conceitos matemáticos. Alimentar com matemática a produção matemática, alimentar com invenção ${ }^{13}$ a cognição e manter a processualidade, uma cognição inventiva. Desestabilizar o modo correto, as verdades prontas, os modelos. Abalar as certezas. Estremecer os discursos. Avaliar o valor dos valores. Produzir valores para a vida e com a vida ao produzir matemática. Inventar a vida produzindo matemática. Inventar um professor ao produzir matemática. Inventar uma professora ao produzir matemática. De novo: formação enquanto inquietude e processualidade na experiência.

Experimentar abordagens metodológicas, exercitando-as. Investigar matematicamente, resolver problemas e ir à história da matemática, como? Com isto, implicado e complicado no fazer. Não dar conta por antecipação. Não dar conta, viver. Fazer das abordagens, presença com o viver. Tatear com a coisa. Experimentar com a coisa. Desacostumar o corpo ao tão famigerado siga o modelo. Nem sequer ter modelo. Fazer a história da matemática deslocar dos discursos dos bem sucedidos. Fazer a história com aquele vivido, naquele vivido. Uma história vivida que dá conta de compreender outras histórias e tantas outras já vividas. Significar um passado histórico do fazer matemático, vivendo. Não viver o mesmo, nem representar o mesmo, nem desconsiderar o já produzido. Num novo viver, atualizar e significar o passado. Criar um corpo que investiga, que erra, que acerta, que negocia, que está com o outro. Fazer da produção matemática problema a ser inventado e, com isso, inventar-se professor e professora.

Educação \& Realidade, Porto Alegre, v. 39, n. 4, p. 1071-1087, out./dez. 2014.1085 Disponível em: <http://www.ufrgs.br/edu_realidade> 
Fazer da Matemática Problema a ser Inventado Inventando Formação

Neste artigo, um vivido de um professar junto a um pesquisar e um vivido de um pesquisar junto a um professar. Um vivido na formação pensada como processualidade implicada em um mundo inventando-se outra neste processo. Movimento de formação: mundo-existência-formação. Junto a isso um cuidado de si como aguilhão que incita, que inquieta o agir, num estar com o mundo na produção de um si. Um si que escapa de um eu. Um si que não conjuga verbos nem é acompanhado por artigo definido. Um si formar. Um si produzir uma ética, produzir uma estética da vida, produzir um obrar. Um si sustentar longe de valores transcendentais. Um si decidir atentar a si. Um si inquietar com o mundo num mundo produzindo mundo. Um si implicado com a formação enquanto inquietude e processualidade na experiência.

Recebido em 25 de março de 2014 Aprovado em 04 de agosto de 2014

\section{Notas}

1 O modo itálico será utilizado para trazer algumas falas (orais ou escritas) daqueles e daquelas que participaram do evento apresentado neste artigo.

2 Fundamentos Teóricos Metodológicos e Prática Escolar I e II.

3 A discussão desta atividade foi realizada Clareto e Rotondo (2014), ainda no prelo.

4 O filme A Guerra do Fogo (La guerre du fue) tem a direção de Jean-Jacques Annaud e roteiro de Gérard Brach, foi produzido por França e Canadá em 1981.

5 Em uma das aulas de uma das turmas aqui apresentadas, a professora, autora deste artigo, ausentou-se por estar em viagem a um congresso. Para dar continuidade ao trabalho já iniciado com a turma solicitou a seu colega, então professor-substituto no Departamento de Educação da UFJF, que estivesse com a turma em uma aula.

6 A UFJF oferece bolsas através do Programa de Monitoria. Os alunos e alunas atuantes neste Programa, chamados monitores, têm um plano de trabalho associado às disciplinas para as quais foram selecionados(as), devendo cumprir uma carga semanal de doze horas. A monitora, atuante neste cenário, era, na época, aluna do Curso de Matemática e dentre as atividades planejadas deveria acompanhar as aulas das disciplinas de Matemática das turmas de Pedagogia citadas anteriormente.

7 O método é tomado junto ao pensamento de Deleuze e Guattari (1995) e visa acompanhar processos. Para a discussão do método da cartografia, modo como vem sendo nomeado, sugerimos Passos, Kastrup e Escóssia (2009).

8 As produções de alunos e alunas destas disciplinas se materializam, muitas vezes, em relatórios, cartazes, poemas, desenhos, teatros, narrativas e outros. É solicitado a eles e a elas que cedam este material para que um campo de uma pesquisa vá se constituindo na processualidade das salas de aulas. No presente artigo há uma opção: a de trazer o vivido de muitas turmas e fazer encontrar, em texto, tempos cronológicos e espaços físicos distintos. Entre tantas, uma turma teve uma de suas aulas gravadas em áudio. Houve o consentimento prévio de alunos e alunas para tal gravação.

1086 Educação \& Realidade, Porto Alegre, v. 39, n. 4, p. 1071-1087, out./dez. 2014 Disponível em: <http://www.ufrgs.br/edu_realidade> 
9 Em algumas turmas trabalhamos com pedaços de lã. Percebemos que este tipo de fio, ao ser manuseado, cedia muito e levava a diferenças nas medidas de perímetro realizadas pelos alunos e pelas alunas. Optamos por usar fios de barbante no intuito de minimizar as diferenças encontradas.

10 A foto 4 traz, à esquerda, parte da anotação realizadas pela monitora em cópia do quadro de uma das turmas. Já à direita, apresentamos outro quadro, noutra turma. As unidades ora recebiam numeração I, II, III,..., noutras recebiam nomes de cores e recebiam, em algumas turmas, a notação u.c. e u.a. representando, respectivamente, unidade de comprimento e unidade de área.

11 Esta conversa aconteceu por e-mail.

12 Para esta discussão veja Gallo (2010).

13 Para Kastrup (1999) a cognição guarda uma instabilidade intrínseca e é aí que a invenção opera. Invenção compreendida como "a potência que a cognição tem de diferir de si mesma, de transpor seus próprios limites” (p. 55).

\section{Referências}

CASTRO, Edgardo. Vocabulário de Foucault: um percurso de seus temas, conceitos e autores. Belo Horizonte: Autêntica, 2009.

CLARETO, Sônia Maria; ROTONDO, Margareth Sacramento. Como seria um mundo sem matemática? Hein!?: tensão entre narrativa-verdade. Bolema (Boletim de Educação Matemática), Rio Claro, UNESP, 2014.

DELEUZE, Gilles. A Ilha Deserta. São Paulo: Iluminuras, 2006.

DELEUZE, Gilles; GUATTARI, Félix. Mil Platôs: capitalismo e esquizofrenia. Tradução de A. Guerra Neto e C.P. Costa. Rio de Janeiro: Editora 34, 1995.

FOUCAULT, Michel. Estratégia, Poder-Saber (Ditos e Escritos, vol. IV). Rio de Janeiro: Forense Universitária, 2003.

FOUCAULT, Michel. A Hermemêutica do Sujeito. Tradução de Márcio Alves da Fonseca e Salma Tannus Muchail. São Paulo: Martins Fontes, 2006.

GALLO, Sílvio. Filosofias da Diferença e Educação: o revezamento entre teoria e prática. In: CLARETO, Sônia Maria; FERRARI, Anderson (Org.). Foucault, Deleuze e Educação. Juiz de Fora: Editora UFJF, 2010. P. 49-63.

KASTRUP, Virgínia. A Invenção de si e do Mundo: uma introdução do tempo e do coletivo no estudo da cognição. Campinas: Papirus, 1999.

LISPECTOR, Clarice. Água Viva. Rio de Janeiro: Rocco, 1998.

PASSOS, Eduardo; KASTRUP, Virgínia; ESCÓSSIA, Liliana da (Org.). Pistas do Método da Cartografia: pesquisa intervenção e produção de subjetividade. Porto Alegre: Sulina, 2009.

Margareth Aparecida Sacramento Rotondo é doutora em Educação Matemática. Professora da Faculdade de Educação e do Programa de Pós-graduação em Educação da Universidade Federal de Juiz de Fora. Pesquisadora CAPES/FAPEMIG. Líder do Travessia Grupo de Pesquisa e pesquisadora no Grupo de Pesquisa Núcleo de Educação em Ciência, Matemática e Tecnologia, ambos cadastrados no CNPq. Coordenadora do Núcleo de Educação em Ciência, Matemática e Tecnologia (NEC) da Faculdade de Educação da UFJF.

E-mail: margarethrotondo@gmail.com

Educação \& Realidade, Porto Alegre, v. 39, n. 4, p. 1071-1087, out./dez. 2014.1087 Disponível em: <http://www.ufrgs.br/edu_realidade> 